320860

\title{
Determining the Surface Structure of Silicated Alumina Catalysts via Isotopic Enrichment and Dynamic Nuclear Polarization Surface-Enhanced NMR Spectroscopy
}

\author{
Andrew G. M. Rankin, ${ }^{1}$ Paul B. Webb, ${ }^{1,2 *}$ Daniel M. Dawson, ${ }^{1}$ Jasmine Viger-Gravel, ${ }^{3}$ \\ Brennan J. Walder, ${ }^{3}$ Lyndon Emsley ${ }^{3}$ and Sharon E. Ashbrook ${ }^{*}$
}

${ }^{1}$ School of Chemistry, EaStCHEM and Centre of Magnetic Resonance, University of St Andrews, St Andrews KY16 9ST, UK

${ }^{2}$ Sasol UK Ltd, Purdie Building, North Haugh, St Andrews KY16 9ST, UK Institut des Sciences et Ingénierie Chimiques, Ecole Polytechnique Fédérale de Lausanne, CH1015 Lausanne, Switzerland

*Authors to whom correspondence should be addressed.

E-mail: sema@st-andrews.ac.uk, pbw@@st-andrews.ac.uk

Submitted to J. Phys. Chem. C 


\section{Abstract}

Isotopic enrichment of ${ }^{29} \mathrm{Si}$ and DNP-enhanced NMR spectroscopy are combined to determine the detailed surface structure of a silicated alumina catalyst. The significant sensitivity enhancement provided by DNP is vital to the acquisition of multinuclear and multidimensional experiments that provide information on the atomic-level structure of the species present at the surface. Isotopic enrichment not only facilitates spectral acquisition, particularly given the low (1.5 wt\%) Si loading, but also enables spectra with higher resolution than those acquired using DNP to be obtained. The unexpected similarity of conventional, CP and DNP NMR spectra is attributed to the presence of adventitious surface water that forms a sufficiently dense ${ }^{1} \mathrm{H}$ network at the silica surface so as to mediate efficient polarization transfer to all Si species regardless of their chemical nature. Spectra reveal the presence of Si-O-Si linkages at the surface (identified as $\mathrm{Q}^{4}(3 \mathrm{Al})$ $\left.\mathrm{Q}^{4}(3 \mathrm{Al})\right)$, and confirm that the anchoring of the surface overlayer with the alumina occurs through $\mathrm{Al}^{\mathrm{IV}}$ and $\mathrm{Al}^{\mathrm{V}}$ species only. This suggests the presence of $\mathrm{Q}^{3} / \mathrm{Q}^{4} \mathrm{Si}$ at the surface affects the neighbouring Al species, modifying the surface structure and making it less likely $\mathrm{Al}{ }^{\mathrm{VI}}$ environments are in close spatial proximity. In contrast, $\mathrm{Q}^{1} / \mathrm{Q}^{2}$ species, bonded to the surface by fewer covalent bonds, have less of an effect on the surface and more $\mathrm{Al}$ VI species are consequently found nearby. The combination of isotropic enrichment and DNP provides a definitive and fully quantitative description of the Si-modified alumina surface, and we demonstrate that almost a third of the silicon at the surface is connected to another Si species, even at the low level of coverage used, lowering the propensity for the formation of Brønsted acid sites. This suggests that a variation in the synthetic procedure might be required to obtain a more even coverage for optimum performance. The work here will allow for more rigorous future investigations of structure-function relationships in these complex materials. 


\section{Introduction}

Silicated aluminas are commonly employed as solid acid catalysts, with applications in a number of processes ranging from ethanol dehydration to hydrocarbon cracking and skeletal isomerization. ${ }^{1-4}$ The presence of both $\mathrm{Si}$ and $\mathrm{Al}$ at the surface generates the mild acidity that is essential to catalytic behaviour, ${ }^{1}$ but the exact structure of these acidic environments is still debated. ${ }^{2-4}$ Early studies of catalytic cracking postulated that Brønsted acidity is attributable to aluminol groups in close proximity to silanols 5 or protons that compensate for the negative charge at the surface. ${ }^{6-7}$ More recent investigations (primarily using IR spectroscopy, probe molecule adsorption and ${ }^{1} \mathrm{H}$ MAS NMR spectra) propose that the catalytic acid sites are bridging Si-OH-Al groups ${ }^{8-10}$ or silanols in the vicinity of $\mathrm{Al}^{\mathrm{III}}, \mathrm{Al}^{\mathrm{IV}}$ or $\mathrm{Al}^{\mathrm{V}}{ }^{2,3}$ Identifying the true origins of the catalytic response demands an atomic-level description of the reactive surface, but this is far from trivial. The difficulty lies partly in the diverse range of possible surface structures and the typically amorphous character of the materials - for example, the catalytic surface does not display sufficient long-range order to permit structure determination via diffraction-based methods. ${ }^{11}$ Vibrational spectroscopy can provide information on the presence of various structural motifs, using molecular probes, but the spectra obtained are often highly complex, leading to difficult and subjective data interpretation. Furthermore, the connectivity between $\mathrm{Si}$ and $\mathrm{Al}$ is not easily assessed using this approach. ${ }^{12-14}$

While solid-state NMR spectroscopy is ideally suited to investigating the Si-Al connectivity, as it has no requirement for long-range order and is sensitive to small changes in local chemical environments, ${ }^{15-18}$ the technique suffers from several practical drawbacks. The inherently low natural abundance of ${ }^{29} \mathrm{Si}(4.7 \%)$ requires extended acquisition times to obtain spectra with acceptable sensitivity. For many silicated aluminas, this problem is compounded by the low amount of $\mathrm{Si}$, presenting an additional challenge for the implementation of more complex multinuclear and multidimensional experiments. ${ }^{19}$ Furthermore, the suitability of conventional ${ }^{27} \mathrm{Al}$ NMR spectroscopy for the characterization of alumina-based catalysts is debatable, since the majority of signals 
reflect coordination geometries of the bulk rather than the nature of the surface that is responsible for the reaction chemistry. ${ }^{20}$

Recent years have seen a step change in the sensitivity of NMR experiments through the introduction of dynamic nuclear polarization (DNP), where magnetization is transferred from unpaired electrons to nearby nuclei. ${ }^{21-22}$ In typical, modern DNP experiments for materials, an exogenous solution of a nitroxide biradical in a glassforming solvent is introduced as a polarization source using incipient wetness impregnation. ${ }^{23-24}$ Saturation of the EPR transitions using continuous microwave irradiation polarizes the protons in the solvent, typically via the cross effect. ${ }^{25-26}$ Proton spin diffusion distributes this enhanced nuclear polarization across the solvent phase, from where it can be transferred to less receptive nuclei using conventional cross polarization $(\mathrm{CP})$. This greatly enhances the polarization of surface species relative to the bulk, leading to this approach being referred to as DNP Surface-Enhanced NMR Spectroscopy or DNP-SENS. ${ }^{23-24}$ Owing to the high signal enhancements available (over two orders of magnitude in favourable cases), DNP can overcome the inherently poor sensitivity of many NMR experiments and is being applied increasingly to probe the detailed surface structure of a diverse range of materials.

In recent years, the sensitivity of DNP has provided some new insights into the nature of the interface between $\mathrm{Si}$ and $\mathrm{Al}$ in catalytically important amorphous silicated aluminas. ${ }^{27-30}$ This has included the observation (using ${ }^{29} \mathrm{Si} \mathrm{NMR}$ ) of isolated $\mathrm{SiOH}$ species on the surface, 27,28 the presence of Brønsted acid sites (and the determination of the O-H bond lengths) ${ }^{29}$ and some insight into the $\mathrm{Al} / \mathrm{Si}$ connectivity using two-dimensional correlation experiments. ${ }^{30}$ However, the determination of true structure-function relationships requires a fully quantitative description of surface structure, which has not yet been able to be demonstrated, and is the focus of the present work. The DNP enhancement factor, $\varepsilon$, is determined from the ratio of signal intensities with and without microwave irradiation, and is dependent on temperature, microwave power, concentration of the exogenous radical source and the extent of surface wetting. ${ }^{21-22}$ 
However, proton density also has a significant effect on the absolute amount of signal observed, a direct consequence of the complex pathway of polarisation transfer from the electron to the target nucleus. Given the expected dependence of the ${ }^{1} \mathrm{H}-29 \mathrm{Si} \mathrm{CP}$ transfer efficiency on the local proton density it would be expected that signal intensities would be highly dependent on the proximity of a nucleus to hydroxyl groups at the sample surface. $^{24}$ Resonances from lower-order $Q^{n}$ species (where $Q^{n}$ denotes a species of structure $\left.\mathrm{Si}(\mathrm{OT})_{\mathrm{n}}(\mathrm{OH})_{4-n}\right)$, which possess a higher local proton density, are expected to be amplified to a greater extent than higher-order $\mathrm{Q}^{\mathrm{n}}$ analogues. This potential variation in signal enhancement should, therefore, limit DNP (and similarly CP) measurements to a qualitative, or at best semi-quantitative, description of surface structure, which in turn places limitations on the determination of accurate structure-function relationships. Such effects of proton proximity are clearly demonstrated by the work of Lelli et al., who investigated phenol functionalised silica surfaces. ${ }^{24}$ At very short contact times, only ${ }^{29} \mathrm{Si}$ centres in close proximity to ${ }^{1} \mathrm{H}$ were enhanced. Signal intensity associated with $\mathrm{Q}^{\mathrm{n}}$ sites that are further removed from ${ }^{1} \mathrm{H}$ increased with longer $\mathrm{CP}$ mixing times as polarisation was transferred from more distant spins.

While the expected variation in CP and DNP signal intensity with local proton density may limit these approaches to providing a more qualitative description of surface structure it would, nonetheless, offer important and detailed information on the atomicscale environment, which can be vital for spectral assignment. Ideally, therefore, spectra edited on the basis of spatial proximity would be compared to more quantitative spectra (i.e., using conventional experiments that do not rely on any polarization transfer and have sufficiently long recycle intervals to account for any differences in relative relaxation). The obvious solution here is to exploit isotopic enrichment, improving the sensitivity of the conventional NMR experiment to such an extent that spectra can be acquired on a reasonable timescale, and spectral lineshapes can then be compared to those acquired using $\mathrm{CP} / \mathrm{DNP}$. Enrichment also has additional advantages for the sensitivity of heteronuclear, and particularly homonuclear, two-dimensional correlation NMR 
experiments, made possible using DNP but ultimately limited by the low abundance of NMR-active Si species.

In this work, we exploit both isotopic enrichment of ${ }^{29} \mathrm{Si}$ and DNP enhancement to determine the detailed surface structure of a $\mathrm{Si}-\gamma-\mathrm{Al}_{2} \mathrm{O}_{3}$ material with $1.5 \mathrm{wt} \% \mathrm{Si}$ doping. This combined strategy enables us not only to obtain the quantitative NMR spectra that are so key to understanding surface structure, but also to exploit the significant sensitivity advantages offered by DNP and acquire multidimensional experiments that simply would not be possible otherwise. The combination of these two approaches enables a confident spectral assignment and the determination of the type and more importantly, the proportion, of surface species present. The understanding we have gained here will be used to direct future synthetic approaches for surface modification of similar materials, confident that subsequent quantitative analysis will be possible using the approaches introduced in this work, and insight into the structure-function relationships for aluminabased catalysts can then be unveiled.

\section{Experimental Details}

Synthesis: $\mathrm{Si}-\gamma-\mathrm{Al}_{2} \mathrm{O}_{3}(1.5 \mathrm{wt} \% \mathrm{Si})$ materials were synthesized by a conventional wet impregnation procedure. $\gamma-\mathrm{Al}_{2} \mathrm{O}_{3}(\mathrm{Sasol}, 98 \%)$ was impregnated with either conventional (Sigma-Aldrich, 98\%) or 99\% 29Si-enriched (Cortecnet, >95\%) tetraethyl orthosilicate dissolved in dry ethanol, in an inert (Ar) atmosphere. Samples were then dried at $60{ }^{\circ} \mathrm{C}$ in vacuo and subsequently calcined in air at $520{ }^{\circ} \mathrm{C}$ for $2 \mathrm{~h}\left(\right.$ ramp rate of $\left.10{ }^{\circ} \mathrm{C} \mathrm{min}-1\right)$. The final composition was confirmed by elemental analysis (ICP OES, see Supporting Information). The initial alumina contained spherical particles with an average diameter of $75 \mu \mathrm{m}$. The silicated aluminas were characterised using $\mathrm{N}_{2}$ adsorption measurements (see Supporting Information). Dehydrated ${ }^{29} \mathrm{Si}$-enriched $\mathrm{Si}-\gamma-\mathrm{Al}_{2} \mathrm{O}_{3}$ was dried in vacuo $\left(150{ }^{\circ} \mathrm{C}\right.$, $\sim 12 \mathrm{~h}$ ) and subsequently packed into a $4 \mathrm{~mm} \mathrm{ZrO}_{2}$ rotor in an inert $\left(\mathrm{N}_{2}\right)$ atmosphere. 
NMR spectroscopy: NMR spectra were acquired using a Bruker Avance III spectrometer, equipped with a 9.4 T widebore magnet operating at Larmor frequencies of $400.13 \mathrm{MHz}$ for ${ }^{1} \mathrm{H}, 104.3 \mathrm{MHz}$ for ${ }^{27} \mathrm{Al}$ and $79.46 \mathrm{MHz}$ for ${ }^{29} \mathrm{Si}$. Powdered samples were packed into 4 $\mathrm{mm} \mathrm{ZrO}_{2}$ rotors and rotated at magic angle spinning (MAS) rates of 10 to $14 \mathrm{kHz}$, using a conventional $4 \mathrm{~mm} \mathrm{HX}$ probe. Spectra were acquired using radiofrequency field strengths of $\sim 90 \mathrm{kHz}$ for ${ }^{1} \mathrm{H}, \sim 110 \mathrm{kHz}$ for ${ }^{27} \mathrm{Al}$ and $\sim 80 \mathrm{kHz}$ for ${ }^{29} \mathrm{Si}$. Typical recycle intervals were 1 $\mathrm{s}$ for ${ }^{1} \mathrm{H}, 3 \mathrm{~s}$ for ${ }^{27} \mathrm{Al}$ and $120 \mathrm{~s}$ for ${ }^{29} \mathrm{Si}$. (For ${ }^{29} \mathrm{Si} \mathrm{NMR}, \mathrm{T}_{1}$ values were estimated to be much longer than $120 \mathrm{~s}$, as discussed in a later section, but little difference in relative relaxation was observed). ${ }^{1} \mathrm{H}$ spectra were acquired using the DEPTH pulse sequence for probe background suppression. ${ }^{31}{ }^{29} \mathrm{Si}$ spectra were acquired using either single pulse excitation (DP), DEPTH pulse sequences or cross polarization. For CP spectra, transverse magnetization was obtained from ${ }^{1} \mathrm{H}$ using contact pulse durations of between 0.1 and 10 ms (ramped $90-100 \%$ for $\left.{ }^{1} \mathrm{H}\right)$ and a recycle interval of $1 \mathrm{~s}$. TPPM ${ }^{1} \mathrm{H}$ decoupling $(\sim 90 \mathrm{kHz})^{32}$ was applied during acquisition. For ${ }^{1} \mathrm{H}-29 \mathrm{Si}$ CP HETCOR NMR spectra, contact pulse durations of 0.5 and $3 \mathrm{~ms}$ were used. Sign discrimination in the indirect dimension was achieved using the quadrature detection method of Marion et al. ${ }^{33}{ }^{27} \mathrm{Al}$ spectra were obtained using either single pulse excitation or CP. For CP spectra, transverse magnetization was obtained from ${ }^{1} \mathrm{H}$ using a contact pulse duration of $0.8 \mathrm{~ms}$ (ramped for ${ }^{1} \mathrm{H}$ ) and a recycle interval of $1 \mathrm{~s}$. Chemical shifts are shown (quoted in ppm) relative to $\left(\mathrm{CH}_{3}\right)_{4} \mathrm{Si}$ for ${ }^{1} \mathrm{H}$ and ${ }^{29} \mathrm{Si}$ and $1 \mathrm{M} \mathrm{Al}\left(\mathrm{NO}_{3}\right)_{3}$ (aq) for ${ }^{27} \mathrm{Al}$, measured using secondary references of L-alanine for ${ }^{1} \mathrm{H}\left(\mathrm{NH}_{3} \delta=8.5 \mathrm{ppm}\right)$, octakis(trimethylsiloxy)silsesquioxane (Q8M8) for ${ }^{29} \mathrm{Si}\left(\mathrm{OSi}\left(\mathrm{CH}_{3}\right)_{3} \delta=11.5 \mathrm{ppm}\right)$ and aluminium acetylacetonate for ${ }^{27} \mathrm{Al}\left(\delta_{\text {iso }}=0.0\right.$ ppm, $\left.\mathrm{C}_{\mathrm{Q}}=3.0 \mathrm{MHz}, \eta_{\mathrm{Q}}=0.16\right)$.

DNP NMR experiments were performed using a Bruker Avance I spectrometer, equipped with a $9.4 \mathrm{~T}$ widebore magnet operating at Larmor frequencies of $400.21 \mathrm{MHz}$ for ${ }^{1} \mathrm{H}, 104.29 \mathrm{MHz}$ for ${ }^{27} \mathrm{Al}$ and $79.50 \mathrm{MHz}$ for ${ }^{29} \mathrm{Si}$. A 9.7 $\mathrm{T}$ gyrotron magnet was utilized for the generation of microwaves, operating at a frequency of $263 \mathrm{GHz}$. The field of the main $(9.4 \mathrm{~T})$ magnet was set such that microwave irradiation occurred at the ${ }^{1} \mathrm{H}$ positive enhancement maximum of nitroxide biradicals. Incipient wetness impregnation of 
powdered samples $(\sim 25 \mathrm{mg})$ was performed with a solution $(16-24 \mu \mathrm{l})$ of the nitroxide biradical polarizing agent TEKPol in 1,1,2,2-tetrachloroethane (TCE) (14-16 mM). ${ }^{34-35}$ Impregnated samples were packed into $3.2 \mathrm{~mm}$ sapphire or $\mathrm{ZrO}_{2}$ rotors, and frozen at 100 $\mathrm{K}$ inside a $3.2 \mathrm{~mm}$ low-temperature MAS probe using dry $\mathrm{N}_{2}$ as the bearing and drive gas. Samples were typically subjected to multiple thawing cycles by ejecting the sample into the catcher in the room temperature region of the probe, in order to minimize the amount of oxygen in the biradical solution (which would decrease DNP enhancements). ${ }^{36}$ Samples were rotated at MAS rates between 8 and $12.5 \mathrm{kHz}$. Ramped (90-100 or 80-100\%) CP was used to transfer polarization from ${ }^{1} \mathrm{H}$ to ${ }^{29} \mathrm{Si}$ or ${ }^{27} \mathrm{Al}$. SPINAL ${ }^{1} \mathrm{H}$ decoupling ${ }^{37}$ was applied during acquisition. For ${ }^{1} \mathrm{H}^{-27} \mathrm{Al} \mathrm{CP}$ experiments, a low-power ${ }^{27} \mathrm{Al}$ radiofrequency field was used to ensure efficient spin locking of the quadrupolar nucleus. ${ }^{38-39}$ Typical DNP enhancements (calculated by comparing spectra acquired with and without microwave irradiation) were $\varepsilon=92\left({ }^{29 S i}\right)$ and $\varepsilon=112\left({ }^{27} \mathrm{Al}\right)$. Two-dimensional (2D) ${ }^{29 S i-29 S i ~ d o u b l e-~}$ quantum correlation spectra were acquired using a refocused INADEQUATE experiment ${ }^{40}$ using $\tau_{\mathrm{J}}$ intervals of between 3.2 and $16 \mathrm{~ms}$. 2D ${ }^{29} \mathrm{Si}^{-27} \mathrm{Al}$ scalar (throughbond) correlation spectra were acquired with a refocused J-INEPT experiment, ${ }^{41}$ and a $\tau_{\mathrm{J}}$ interval of $6 \mathrm{~ms} .2 \mathrm{D}{ }^{29} \mathrm{Si}-27 \mathrm{Al}$ dipolar (through-space) correlation spectra were acquired with a dipolar refocused D-INEPT experiment, ${ }^{42}$ using REDOR $^{43}$ for heteronuclear ${ }^{29} \mathrm{Si}-27 \mathrm{Al}$ dipolar recoupling. In all cases, initial ${ }^{29} \mathrm{Si}$ polarization was generated via ${ }^{1} \mathrm{H}-29 \mathrm{Si}$ $\mathrm{CP}$ with contact pulse durations of between 3 and $3.5 \mathrm{~ms}$. For all 2D experiments, the quadrature detection method of States et al. ${ }^{44}$ was used to achieve sign discrimination in the indirect dimension. Chemical shifts are shown (quoted in ppm) relative to $\left(\mathrm{CH}_{3}\right){ }_{4} \mathrm{Si}\left({ }^{1} \mathrm{H}\right.$ and $\left.{ }^{29} \mathrm{Si}\right)$ and $1.0 \mathrm{M} \mathrm{Al}\left(\mathrm{NO}_{3}\right)_{3}(\mathrm{aq})\left({ }^{27} \mathrm{Al}\right)$, measured using an internal reference of $\mathrm{TCE}\left({ }^{1} \mathrm{H} \delta\right.$ $=6.2$ ppm). Lineshape fitting was carried out using dmfit. ${ }^{45}$

\section{Results and Discussion}

Figure 1 shows ${ }^{29} \mathrm{Si}$ MAS NMR spectra of $99 \%{ }^{29} \mathrm{Si}$ enriched $\mathrm{Si}-\gamma-\mathrm{Al}_{2} \mathrm{O}_{3}(1.5 \mathrm{wt} \% \mathrm{Si})$, acquired using direct polarization (DP), CP and DNP. All DP and CP experiments were carried out at room temperature $(298 \mathrm{~K})$ on samples with no radical added, while DNP 
experiments were carried out at low temperature (100 K). Given the inherently nonquantitative nature of $\mathrm{CP}$ and the additional surface sensitivity of DNP, the spectral lineshapes are remarkably similar (as shown in the Supporting Information (Figure S1), where the lineshapes are overlaid). The DP and CP spectra exhibit better resolution than the DNP spectrum (although the DP spectrum has poorer sensitivity), as a result either of increased relaxation arising from the presence of the radical or, more likely, owing to the lower temperature of the experiments (and reduced molecular motion), leading to a broader distribution of shifts. Despite the much greater sensitivity of the DNP spectrum, it is not possible to decompose the lineshape unambiguously into individual components. However, four distinct environments are discernable in the DP and CP NMR spectra three sharp components at high frequency and a lower intensity, broader resonance at lower frequency. It is worth noting that the DP spectrum would have taken $\sim 311$ days to acquire at natural abundance (see Supporting Information Figure S2). Figure 2 shows the variation in the spectrum as a function of the $\mathrm{CP}$ contact time, $\tau_{\mathrm{CP}}$. In contrast to the materials studied in Ref. 24, there are only very small differences in the spectral lineshape as $\tau_{\mathrm{CP}}$ increases. It is not clear if this result suggests that no $\mathrm{Q}^{4}$ species are present (i.e., all $\mathrm{Si}$ are connected to at least $1 \mathrm{OH}$ group), certainly possible at the low weight loading considered here. ${ }^{46-47}$ It is difficult to assign species in this spectrum simply on the basis of $\delta$, as the expected -10 ppm change with the number of coordinated bridging oxygen species is complicated in aluminosilicates by an additional shift to higher frequency of 5 to 8 ppm per next nearest neighbor (NNN) Al. ${ }^{48-49}$ Therefore, it is not possible to unambiguously confirm the presence, or absence, of $\mathrm{Q}^{4}$ species in the spectra of $\mathrm{Si}-\gamma-\mathrm{Al}_{2} \mathrm{O}_{3}$, although the signal observed extends over the region expected for these species.

The features in the DP and CP spectral lineshapes in Figure 1 do suggest that different $\mathrm{Q}^{\mathrm{n}}$ species are present, making it all the more surprising that little variation in the lineshape is observed either between the two experiments or as a function of the $\mathrm{CP}$ contact time. It is clear from Figure 2 that the polarization transfer in CP remains equally efficient for all species, irrespective of the number of hydroxyl groups attached. However, it is possible that the presence of adventitious surface water, known to form extensive and 
strong H-bonding with silanols, ${ }^{50-51}$ could affect the spectral intensities observed. To determine if this adventitious water is playing a role in the CP dynamics the ${ }^{29} \mathrm{Si}$ enriched $\mathrm{Si}-\gamma-\mathrm{Al}_{2} \mathrm{O}_{3}$ was dehydrated in vacuo at $150{ }^{\circ} \mathrm{C}$ and packed into a $\mathrm{ZrO}_{2}$ rotor in a glovebox. Relatively mild conditions were used for dehydration to avoid any surface dehydroxylation. Verification of dehydration was obtained using ${ }^{1} \mathrm{H}$ MAS NMR, as shown in the Supporting Information, Figure S3. Figure 2b compares the ${ }^{29}$ Si CP MAS spectra of hydrated and dehydrated $\mathrm{Si}-\gamma-\mathrm{Al}_{2} \mathrm{O}_{3}$ and reveals a change in the relative intensities of the spectral components, with an increase in signal intensity of the peak at $\delta=-78$ ppm, confirming the higher density of $\mathrm{OH}$ groups. The DP and CP spectra of dehydrated Si- $\gamma-$ $\mathrm{Al}_{2} \mathrm{O}_{3}$ are less similar, as shown in Figure $\mathrm{S} 4$ of the Supporting Information, with a relative increase in the intensity of the signal at higher $\delta$ in the $\mathrm{CP}$ spectrum. Crucially, the DP NMR spectrum remains largely unaffected by dehydration, an indication that surface structure has remained intact following the high temperature treatment (Supporting Information, Figure S5). From these observations, it is clear in this case that the H-bonded water forms a sufficiently dense ${ }^{1} \mathrm{H}$ network at the silica surface as to mediate efficient polarization transfer to all $\mathrm{Si}$ species regardless of their chemical nature and $\mathrm{OH}$ functionality.

Figure 3a compares ${ }^{1} \mathrm{H}-29 \mathrm{Si}$ CP HETCOR NMR spectra of hydrated and dehydrated $\mathrm{Si}-\gamma-\mathrm{Al}_{2} \mathrm{O}_{3}$ materials, and shows appreciable differences in the extent of correlation between ${ }^{29} \mathrm{Si}$ and ${ }^{1} \mathrm{H}$ upon the removal of water. When dehydrated, higher-order $\mathrm{Q}^{\mathrm{n}}$ species no longer correlate with surface protons because, in the absence of surface water, the $29 \mathrm{Si}$ spectrum is influenced more significantly by local proton (hydroxyl) density. It is clear from Figure $3 b$ that dehydration also results in a more significant variation in the spectral lineshape with contact time. At sufficiently long contact times, correlations to all Si species are observed, but intensity is lost from the region between -85 and -100 ppm as contact time is reduced. Therefore, we conclude that $\mathrm{Q}^{4}$ species are, most likely, present at the silicated surface and, importantly, that the extent of signal amplification remains constant, irrespective of local hydroxyl density, by virtue of adventitious adsorbed water when the sample is hydrated (or stored under ambient conditions). Thus, perhaps 
surprisingly, as long as the surface remains sufficiently hydrated, as is the case here, DNP NMR spectra of such materials may be interpreted quantitatively and an accurate description of structure-function relationships can be obtained.

The combination of ${ }^{29} \mathrm{Si}$ isotopic enrichment and DNP NMR spectroscopy results in a significant signal enhancement that provides access to two-dimensional experiments that may otherwise require prohibitively long acquisition times. In particular, correlations exploiting through-bond J couplings can be valuable sources of information on the nature of the surface structure. Figure $4 \mathrm{a}$ shows a ${ }^{29} \mathrm{Si} \mathrm{CP}$ MAS INADEQUATE ${ }^{40}$ DNP SENS spectrum of hydrated $\mathrm{Si}-\gamma-\mathrm{Al}_{2} \mathrm{O}_{3}(1.5 \mathrm{wt} \% \mathrm{Si})$. Despite the low $\mathrm{Si}$ content, the use of isotopic enrichment combined with DNP permits spectral acquisition in only 4 hours. Signal is observed between -80 and $-100 \mathrm{ppm}$, suggesting that only higher-order $\mathrm{Q}^{\mathrm{n}}$ species are connected to Si, i.e., the three sharper peaks at more positive shift result from isolated $\mathrm{Q}^{\mathrm{n}}(\mathrm{nAl})$ species. Signal is observed over a range of $\sim 20 \mathrm{ppm}$ in $\delta_{1}$, possibly indicating that this results from more than one chemical species, e.g., $\mathrm{Q}^{3}$ and $\mathrm{Q}^{4}$ species. However, the correlation peak lies primarily along the $\delta_{1}=2 \delta_{2}$ diagonal in the twodimensional spectrum, confirming that Si species are only covalently connected to those with very similar shift and, hence, very similar environments. This would suggest the signal probably arises from only $\mathrm{Q}^{4} / \mathrm{Q}^{4}$ or $\mathrm{Q}^{3} / \mathrm{Q}^{3}$ correlations (rather than $\mathrm{Q}^{4} / \mathrm{Q}^{3}$ for example), and the loss of signal at -90 ppm at longer $\tau_{\mathrm{CP}}$ times in the ${ }^{1} \mathrm{H}-29 \mathrm{Si}$ HETCOR spectrum in Figure $3 b$ supports a more likely assignment of $\mathrm{Q}^{4} / \mathrm{Q}^{4}$ species for this peak. Spectra acquired with a variety of J evolution times (shown in the Supporting Information, Figure S6) also show only autocorrelation signal. Projections of the spectra onto the $\delta_{2}$ axis (shown in Figure $4 b$ ) show that signal shifts to higher $\delta$ as $\tau_{\mathrm{J}}$ increases, indicating a positive correlation between ${ }^{29} \mathrm{Si}$ nuclear shielding and the homonuclear J coupling. Such a correlation has also been observed for other (alumino)silicate materials, and was related to changes in the Si-O- Si bond angle using ab initio cluster calculations. ${ }^{52-53}$ While it was shown that the exact values of $\delta$ and J vary with the cations present (and so cannot be directly related to the materials studied here), it seems likely that the same structural change is likely to be responsible, thus suggesting that the Si-O-Si bond angle is 
decreasing $\left(\right.$ by $\sim 7-8^{\circ}$ ) between the signals seen at -93 ppm (when $\tau_{\mathrm{J}}=3.2 \mathrm{~ms}$ ) and $-85 \mathrm{ppm}$ (when $\tau_{\mathrm{J}}=16 \mathrm{~ms}$ ).

To understand the interfacial chemistry between the silica surface overlayer and the $\gamma-\mathrm{Al}_{2} \mathrm{O}_{3}$ structure upon which it resides, heteronuclear correlation experiments $\left({ }^{29} \mathrm{Si}-27 \mathrm{Al}\right.$ refocused INEPT ${ }^{41}$ ) were performed, again exploiting DNP to improve sensitivity. This experiment can probe scalar (through-bond) connectivity, or can be adapted in the solid state to actively recouple the dipolar interaction and provide information on throughspace proximities. Figure 5 a shows a ${ }^{29} \mathrm{Si}^{27} \mathrm{Al}$ dipolar INEPT DNP NMR spectrum of hydrated $\mathrm{Si}-\gamma-\mathrm{Al}_{2} \mathrm{O}_{3}$, acquired using REDOR to recouple the dipolar interaction. ${ }^{43}$ This reveals that $\mathrm{Si}$ is close in space to four-, five and six-coordinate $\mathrm{Al}$ (i.e., $\mathrm{Al}^{\mathrm{IV}}, \mathrm{Al}^{\mathrm{V}}$ and $\mathrm{Al}{ }^{\mathrm{VI}}$ ). As $\mathrm{Si}$ is present only as a surface overlayer, the spectrum contains only $\mathrm{Al}$ species that are close to the surface. As shown in the Supporting Information, the ${ }^{27} \mathrm{Al}$ spectrum of bulk $\gamma$ $\mathrm{Al}_{2} \mathrm{O}_{3}$ contains signals that can be attributed to $\mathrm{Al}{ }^{\mathrm{IV}}$ and $\mathrm{Al}{ }^{\mathrm{VI}}$ species only. ${ }^{54-55}$ However, the surface of $\gamma-\mathrm{Al}_{2} \mathrm{O}_{3}$ has been shown to contain $\mathrm{Al}^{\mathrm{V}}$ species. These can be seen using $\mathrm{CP}$, where magnetization is transferred from surface-based ${ }^{1} \mathrm{H}$ species, resulting in additional signal at $\delta \approx 35 \mathrm{ppm}$ (see Supporting Information). DNP NMR spectra have also demonstrated the presence of $\mathrm{Al}^{\mathrm{V}}$ at the surface of $\gamma-\mathrm{Al}_{2} \mathrm{O}_{3} .{ }^{56}$ Using a filtration experiment, where signals close to the surface dephase owing to their stronger dipolar couplings to ${ }^{1} \mathrm{H}$, Lee et al. demonstrated that $\mathrm{Al}^{\mathrm{V}}$ resides only in the first surface layer. The ${ }^{27} \mathrm{Al}$ MAS NMR spectrum of $\mathrm{Si}-\gamma-\mathrm{Al}_{2} \mathrm{O}_{3}$, shown in the Supporting Information, reveals a similar picture, with resonances corresponding to $\mathrm{Al}^{\mathrm{IV}}$ and $\mathrm{Al}^{\mathrm{VI}}$ in the bulk material, while the $\mathrm{CP}$ spectrum also shows the presence of $\mathrm{Al}^{\mathrm{V}}$ at the surface, in agreement with recent work probing the nature of Brønsted acid sites. ${ }^{57}$ Although $\mathrm{Al}^{\mathrm{V}}$ species are found at the surface of unmodified $\gamma-\mathrm{Al}_{2} \mathrm{O}_{3}$, it has been suggested that additional $\mathrm{Al} V$ is formed at the interface between the Si and alumina, with the proportion of these varying with the Si content. Through-bond connectivity can be probed using the ${ }^{29} \mathrm{Si}-{ }^{27} \mathrm{Al}$ INEPT DNP NMR spectrum acquired without dipolar recoupling (Figure 5b). In contrast to the spectrum in Figure 5a, this reveals that $\mathrm{Si}$ is covalently connected via $\mathrm{Al}^{\mathrm{IV}}$ and $\mathrm{Al}^{\mathrm{V}}$ anchor points. Thus, only a spatial proximity to $\mathrm{Al}^{\mathrm{VI}}$ exists. It is also interesting to note from Figure $5 \mathrm{a}$ that $\mathrm{Al}^{\mathrm{IV} / \mathrm{V}}$ 
species show the strongest (through-space) correlation with Si signal near -84 ppm, while $\mathrm{Al}^{\mathrm{VI}}$ species are more strongly correlated with signal at higher $\delta$ (i.e., lower-order $\mathrm{Q}^{\mathrm{n}}$ species), suggesting these are more frequently found in close proximity at the surface.

Extracting quantitative information from the broadened $29 \mathrm{Si}$ resonance observed using DNP NMR is non trivial. The conventional ${ }^{29} \mathrm{Si}$ MAS NMR spectrum of the ${ }^{29} \mathrm{Si}-$ enriched material exhibits better resolution and, when combined with the information obtained from CP spectra, and particularly from the projection of the single-quantum dimension of the INADEQUATE spectra, a more robust deconvolution is possible, as shown in Figure 6, with parameters given in Table 1. Sharp components can be identified at $-77,-80$ and -83 ppm (where constraints on the positions and lineshapes were determined using variable contact time $\mathrm{CP}$ experiments), with a broader component centred at ca. $-89 \mathrm{ppm}$. The position and lineshape of the latter is determined from the INADEQUATE spectra. From previous literature, $15,48-49$ the three sharp signals can be assigned as $\mathrm{Q}^{1}(1 \mathrm{Al})$ (resonance 1$), \mathrm{Q}^{2}(2 \mathrm{Al})$ (resonance 2 ) and $\mathrm{Q}^{3}(3 \mathrm{Al}) / \mathrm{Q}^{4}(4 \mathrm{Al}$ ) (resonance 3) species. The opposing shifts that are induced by increased condensation of Si-O tetrahedra and substitution of $\mathrm{Si}$ with $\mathrm{Al}$ lead to an inevitable overlap of resonance frequencies for some species. For this reason, it is difficult to discriminate between $\mathrm{Q}^{3}(3 \mathrm{Al})$ and $\mathrm{Q}^{4}(4 \mathrm{Al})$ on the basis of chemical shift alone, and it is possible that both species contribute to the signal at $-83 \mathrm{ppm}$. However, the presence of signal at $-83 \mathrm{ppm}$ in the ${ }^{1} \mathrm{H}-$ ${ }^{29} \mathrm{Si}$ HETCOR spectrum in Figure $3 \mathrm{~b}$ at short contact times suggests a significant contribution to the intensity at this point must arise from $\mathrm{Q}^{3}(3 \mathrm{Al})$ Si centres. The projection of the ${ }^{29} \mathrm{Si}$ DNP NMR INADEQUATE spectrum in Figure $4 \mathrm{~b}$ confirms that the component at -89 ppm contains primarily Si species within Si-O-Si linkages. As discussed above, the observation of signal along the autocorrelation diagonal, and the loss of this signal in the ${ }^{1} \mathrm{H}-29 \mathrm{Si} \mathrm{HETCOR}$ spectrum, suggests it results principally from interconnected $\mathrm{Q}^{4}(3 \mathrm{Al})$ species, i.e., $(\mathrm{OAl})_{3} \mathrm{Si}-\mathrm{O}-\mathrm{Si}(\mathrm{OAl})_{3}$ linkages at this loading. At first sight, it is not perhaps clear why most $\mathrm{Q}^{4}$ Si species are linked to a second Si centre. The low loading of Si in these samples ensures that most $\mathrm{Si}$ species are bonded only to $\mathrm{Al}$ (i.e., $\mathrm{Q}^{1}(1 \mathrm{Al}), \mathrm{Q}^{2}(2 \mathrm{Al})$ and $\left.\mathrm{Q}^{3}(3 \mathrm{Al})\right)$. As $\mathrm{Si}$ forms a surface layer on the alumina it is less likely that it embeds to make 
four bonds to the surface $\mathrm{Al}$, and that $\mathrm{Q}^{4} \mathrm{Si}$ species form (primarily, but perhaps not exclusively) when they are able to bond via a bridging oxygen to a second Si species on the surface. ${ }^{57-58}$ As shown in Table 1 , from the spectrum in Figure 6 we find $\mathrm{Q}^{1}(1 \mathrm{Al}) \approx 22 \%$; $\mathrm{Q}^{2}(2 \mathrm{Al}) \approx 14 \% ; \mathrm{Q}^{3}(3 \mathrm{Al}) / \mathrm{Q}^{4}(4 \mathrm{Al}) \approx 34 \%$ and $\mathrm{Q}^{4}(3 \mathrm{Al}) \approx 30 \%$, suggesting that almost a third of the silicon at the surface is connected to another Si species, even at the low level of coverage used. As the Si-O-Si connectivity increases, the propensity for the formation of Brønsted acid sites will diminish. Thus, a variation in the synthetic procedure might be required to obtain a more even coverage for optimum performance. It should be noted that, although the recycle interval used for the ${ }^{29} \mathrm{Si} D P$ MAS spectrum was $120 \mathrm{~s}$, the $\mathrm{T}_{1}$ value was estimated later to be on the order of $\sim 1.5 \mathrm{~h}$, making acquisition of a truly quantitative spectrum practically unfeasible. Although this may result in some uncertainty in the exact proportion of each species present, little difference was observed in the relative relaxation of the different Si species at shorter recycle intervals. Deconvolution of the ${ }^{29} \mathrm{Si}$ spectrum and assignment of the contributions of the component resonances would have been almost impossible using conventional NMR spectroscopy, and difficult by either DNP (owing to the lower resolution) or isotopic enrichment (owing to the lower sensitivity) alone.

\section{Conclusions}

We have exploited a combination of isotopic enrichment and DNP to provide a definitive and fully quantitative description of the surface structure of Si-modified alumina catalysts. Comparison of DP, CP and DNP $295 i$ NMR spectra surprisingly reveal very similar lineshapes, demonstrating that ${ }^{1} \mathrm{H}-{ }^{29} \mathrm{Si} \mathrm{CP}$ transfer efficiency, and the extent of signal enhancement, is constant and independent of the proximity of a nucleus to surface hydroxyl groups. We have attributed this unexpected behaviour to the presence of adventitious surface water in these highly hygroscopic materials. This H-bonded water forms a sufficiently dense ${ }^{1} \mathrm{H}$ network at the silica surface as to mediate efficient polarization transfer to all Si species regardless of their chemical nature and $\mathrm{OH}$ functionality. Upon dehydration, this network is disrupted, and the transfer efficiency 
becomes more dependent on the chemical nature of the species present. This leads to the unforeseen conclusion that, if sufficiently hydrated, CP (and DNP) NMR spectra of the Simodified alumina surface can be interpreted essentially quantitatively, allowing for accurate and detailed determination of structure-function relationships.

Despite the significant sensitivity advantage afforded by DNP, spectra exhibit comparatively lower resolution, most likely as a result of the lower temperature at which experiments are performed. To obtain an accurate deconvolution of the spectral lineshapes, and to determine the relative proportion of each species present, isotopic enrichment, and the acquisition of non DNP-enhanced spectra at the low Si loading present, is vital. However, the combination of DNP and isotopic enrichment provides access to two-dimensional experiments that would otherwise require prohibitively long acquisition times given the low Si content. ${ }^{29} \mathrm{Si}$ INADEQUATE experiments facilitate the identification of $\mathrm{Si}-\mathrm{O}-\mathrm{Si}$ units in the $\mathrm{Si}-\gamma-\mathrm{Al}_{2} \mathrm{O}_{3}$ structure as interconnected $\mathrm{Q}^{4}(3 \mathrm{Al})$ species. Heteronuclear ${ }^{29} \mathrm{Si}^{27} \mathrm{Al}$ INEPT experiments confirm that $\mathrm{Si}$ is present only as a surface overlayer, and reveal that the reaction of TEOS with $\gamma-\mathrm{Al}_{2} \mathrm{O}_{3}$ occurs via condensation reactions at $\mathrm{Al}^{\mathrm{IV}}$ and $\mathrm{Al}^{\mathrm{V}}$ anchoring points. Furthermore, the corresponding dipolar INEPT spectrum suggests that the presence of $\mathrm{Q}^{3} / \mathrm{Q}^{4} \mathrm{Si}$ at the surface affects the neighbouring $\mathrm{Al}$ species, modifying the surface structure and making it less likely $\mathrm{Al}^{\mathrm{VI}}$ environments are in close spatial proximity. In contrast, the presence of $\mathrm{Q}^{1} / \mathrm{Q}^{2}$ species, bonded to the surface by fewer covalent bonds, has less effect and more $\mathrm{Al}^{\mathrm{VI}}$ species are then found nearby.

The combination of the increased amount of information available as a result of the DNP enhancement, and the ability to obtain quantitative spectra using isotopic enrichment, affords a more rigorous quantitative interpretation of $29 \mathrm{Si}$ spectra and a detailed understanding of the nature of Si-alumina interface. The ability to accurately describe surface structure will allow for more rigorous investigations of structure-function relationships and the future design of synthetic protocols that permit a tailoring of surface sites and, ultimately, catalytic performance. 


\section{Supporting Information}

Detailed comparison of the ${ }^{29} \mathrm{Si}$ spectral lineshapes, ${ }^{29} \mathrm{Si} \mathrm{NMR}$ spectra of unenriched silicated alumina, spectra of dehydrated material, INADEQUATE spectra with varying $\tau_{\mathrm{J}}$ and ${ }^{27} \mathrm{Al}$ spectra of pure and silicated alumina catalyst. The Supporting Information is available free of charge on the ACS Publications website at DOI: XXXX.

\section{Acknowledgements}

We would like to thank SASOL and EPSRC (EP/L505079/1) for studentship funding for AGMR. SEA would also like to thank the Royal Society and Wolfson Foundation for a merit award. PBW would like to thank the Royal Society for the award of an Industry Fellowship. The University of Nottingham DNP MAS NMR Facility used in this research was funded by EPSRC and the University of Nottingham, and assistance from the Facility Manager (Subhradip Paul, University of Nottingham) is also acknowledged. This work was also supported by ERC Advanced Grant No. 320860. The research data (and/or materials) supporting this publication can be accessed at DOI: http:/ / dx.doi.org/10.17630/00533fb3-e938-498d-bfe4-f07d82c309d6. 


\section{References}

1. Busca, G. Acid Catalysts in Industrial Hydrocarbon Chemistry. Chem. Rev. 2007, 107, 5366-5410.

2. Trombetta, M.; Busca, G.; Rossini, S.; Piccoli, V.; Cornaro, U.; Guercio, A.; Catani, R.; Willey, R. J. FT-IR Studies on Light Olefin Skeletal Isomerization Catalysis: III. Surface Acidity and Activity of Amorphous and Crystalline Catalysts Belonging to the $\mathrm{SiO}_{2}-\mathrm{Al}_{2} \mathrm{O}_{3}$ System. J. Catal. 1998, 179, 581-596.

3. Crépeau, G.; Montouillout, V.; Vimont, A.; Mariey, L.; Cseri, T.; Maugé, F. Nature, Structure and Strength of the Acidic Sites of Amorphous Silica Alumina: An IR and NMR Study. J. Phys. Chem. B 2006, 110, 15172-15185.

4. Chizallet, C.; Raybaud, P. Pseudo-Bridging Silanols as Versatile Brønsted Acid Sites of Amorphous Aluminosilicate Surfaces. Angew. Chem. Int. Ed. 2009, 48, 2891-2893.

5. Hansford, R. C. Mechanism of Catalytic Cracking. Ind. Eng. Chem. 1947, 39, 849-852.

6. Thomas, C. L. Chemistry of Cracking Catalysts. Ind. Eng. Chem. 1949, 41, 2564-2573.

7. Tamele, M. W. Chemistry of the Surface and the Activity of Alumina-Silica Cracking Catalyst. Discuss. Faraday Soc. 1950, 8, 270-279.

8. Poduval, D. G.; van Veen, J. A. R.; Rigutto, M. S.; Hensen, E. J. M. Brønsted Acid Sites of Zeolitic Strength in Amorphous Silica-Alumina. Chem. Commun. 2010, 46, 3466-3468.

9. Hensen, E. J. M.; Poduval, D. G.; Ligthart, D. A. J. M.; van Veen, J. A. R.; Rigutto, M. S. Quantification of Strong Brønsted Acid Sites in Aluminosilicates. J. Phys. Chem. C, 2010, $114,8363-8374$.

10. Hensen, E. J. M.; Poduval, D. G.; Degirmenci, V.; Ligthart, D. A. J. M.; Chen, W.; Maugé, F.; Rigutto, M. S.; van Veen, J. A. R. Acidity Characterization of Amorphous SilicaAlumina. J. Phys. Chem. C 2012, 116, 21416-21429.

11. Medrud, R. C., Petroleum Catalysts. In Industrial Applications of X-Ray Diffraction. Chung, F. H.; Smith, D. K., Eds.; CRC Press: Boca Raton, 1999.

12. Farneth, W. E.; Gorte, R. J. Methods for Characterizing Zeolite Acidity. Chem. Rev. 1995, 95, 615-635. 
13. Leydier, F.; Chizallet, C.; Chaumonnot, A.; Digne, M.; Soyer, E.; Quoineaud, A.-A.; Costa, D.; Raybaud, P. Brønsted Acidity of Amorphous Silica-Alumina: The Molecular Rules of Proton Transfer. J. Catal. 2011, 284, 215-229.

14. Leydier, F.; Chizallet, C; Costa, D.; Raybaud, P. CO Adsorption on Amorphous SilicaAlumina: Electrostatic or Brønsted Acidity Probe? Chem. Commun. 2012, 48, 4076-4078.

15. MacKenzie, K. J. D.; Smith M. E. Multinuclear Solid-State NMR of Inorganic Materials; Pergamon: Oxford, 2002.

16. Ashbrook, S. E.; Dawson, D. M.; Griffin, J. M. in Solid-State NMR Spectroscopy, in Local Structural Characterisation. Bruce, D.W.; O’Hare, D.; Walton R. I. Eds.; John Wiley \& Sons Ltd, Chichester, 2014.

17. Ashbrook, S. E.; Sneddon, S. New Methods and Applications in Solid-State NMR Spectroscopy of Quadrupolar Nuclei. J. Am. Chem. Soc. 2014, 136, 15440-15456.

18. Moran, R. F.; Dawson, D. M.; Ashbrook, S. E. Exploiting NMR Spectroscopy for the Study of Disorder in Solids. Int. Rev. Phys. Chem. 2017, 36, 39-115.

19. Delak, K. M.; Farrar, T. C.; Sahai, N. ${ }^{29}$ Si NMR Sensitivity Enhancement Methods for the Quantitative Study of Organosilicate Hydrolysis and Condensation. J. Non-Cryst. Solids. 2005, 351, 2244-2250.

20. Wischert, R; Florian, P; Copéret, C; Massiot, D; Sautet, P. Visibility of Al Surface Sites of $\gamma$-Alumina: A Combined Computational and Experimental Point of View. J. Phys. Chem. C. 2014, 118, 15292-15299.

21. Ni, Q. Z.; Daviso, E.; Can, T. V.; Markhasin, E.; Jawla, S. K.; Swager, T. M.; Temkin, R. J.; Herzfeld, J.; Griffin, R. G. High Frequency Dynamic Nuclear Polarization. Acc. Chem. Res. 2013, 46, 1933-1941.

22. Rossini, A. J.; Zagdoun, A.; Lelli, M.; Lesage, A.; Copéret, C.; Emsley, L. Dynamic Nuclear Polarization Surface Enhanced NMR Spectroscopy. Acc. Chem. Res. 2013, 46, 19421951.

23. Lesage, A.; Lelli, M.; Gajan, D.; Caporini, M. A.; Vitzthum, V.; Mieville P.; Alazun, J.; Roussey, A.; Thieuleux, C.; Mehdi, A. et al. Surface Enhanced NMR Spectroscopy by Dynamic Nuclear Polarization. J. Am. Chem. Soc. 2010, 132, 15459-15461. 
24. Lelli, M.; Gajan, D.; Lesage, A.; Caporini, M. A.; Vitzthum, V.; Mieville P.; Heroguel, F.; Rascon, F.; Roussey, A.; Thieuleux, C. et al. Fast Characterization of Functionalized Silica Materials by Silicon-29 Surface-Enhanced NMR Spectroscopy Using Dynamic Nuclear Polarization. J. Am. Chem. Soc. 2011, 133, 2104-2107.

25. Hu, K.-N.; Yu, H.-H.; Swager, T. M. Griffin, R. G. Dynamic Nuclear Polarization with Biradicals. J. Am. Chem. Soc. 2004, 126, 10844-10845.

26. Song, C.; Hu, K.-N.; Joo, C.-G.; Swager, T. M.; Griffin, R. G. TOTAPOL: A Biradical Polarizing Agent for Dynamic Nuclear Polarization Experiments in Aqueous Media. J. Am. Chem. Soc. 2006, 128, 11385-113890.

27. Mouat, A. R.; George, C.; Kobayashi, T.; Pruski, M.; van Duyne, R. P.; Marks, T. J.; Stair, P. C. Highly Dispersed $\mathrm{SiO} x / \mathrm{Al}_{2} \mathrm{O}_{3}$ Catalysts Illuminate the Reactivity of Isolated Silanol Sites. Angew. Chem. Int. Ed. 2015, 54, 13346 -13351.

28. Mouat, A. R.; Kobayashi, T.; Pruski, M; Marks, T. J.; Stair, P. C. Direct Spectroscopic Evidence for Isolated Silanols in $\mathrm{SiO}_{x} / \mathrm{Al}_{2} \mathrm{O}_{3}$ and Their Formation Mechanism. J. Phys. Chem. C 2017, 121, 6060-6064.

29. Perras, F. A.; Wang, Z.; Naik, P.; Slowing, I. I.; Pruski, M. Natural Abundance ${ }^{17}$ O DNP NMR Provides Precise O-H Distances and Insights into the Brønsted Acidity of Heterogeneous Catalysts. Angew. Chem. Int. Ed. 2017, 56, 9165-9169.

30. Valla, M.; Rossini, A. J.; Caillot, M.; Chizallet, C.; Raybaud, P.; Digne, M.; Chaumonnot, A.; Lesage, A.; Emsley, L.; van Bokhoven, J. A. et al. Atomic Description of the Interface between Silica and Alumina in Aluminosilicates through Dynamic Nuclear Polarization Surface-Enhanced NMR Spectroscopy and First-Principles Calculations. J. Am. Chem. Soc. 2015, 137, 10710-10719.

31. Cory, D. G.; Ritchey, W. M. Suppression of Signals from the Probe in Bloch Decay Spectra. J. Magn. Reson. 1988, 80, 128-132.

32. Bennett, A. E.; Rienstra, C. M.; Auger, M.; Lakshmi, K. V.; Griffin, R. G. Heteronuclear Decoupling in Rotating Solids. J. Chem. Phys. 1995, 103, 6951-6958.

33. Marion, D.; Ikura, M.; Tschudin, R.; Bax, A. Rapid Recording of 2D NMR Spectra without Phase Cycling. Application to the Study of Hydrogen Exchange in Proteins. J. Magn. Reson. 1989, 85, 393-399. 
34. Zagdoun, A.; Casano, G.; Ouari, O.; Schwarzwälder, M.; Rossini, A. J.; Aussenac, F.; Yulikov, M.; Jeschke, G.; Copéret, C.; Lesage, A. et al. Large Molecular Weight Nitroxide Biradicals Providing Efficient Dynamic Nuclear Polarization at Temperatures up to $200 \mathrm{~K}$. J. Am. Chem. Soc. 2013, 135, 12790-12797.

35. Zagdoun, A.; Rossini, A. J.; Gajan, D.; Bourdolle, A.; Ouari, O.; Rosay, M.; Maas, W. E.; Tordo, P.; Lelli, M.; Emsley, L. et al. Non-Aqueous Solvents for DNP Surface Enhanced NMR Spectroscopy. Chem. Commun. 2012, 48, 654-656.

36. Kubiki, D. J.; Casano, G.; Schwarzwälder, M.; Abel, S.; Sauvée, C.; Ganesan, K.; Yulikov, M.; Rossini, A. J.; Jeschke, G.; Copéret, C. et al. Rational Design of Dinitroxide Biradicals for Efficient Cross-Effect Dynamic Nuclear Polarization. Chem. Sci. 2016, 7, 550558.

37. Fung, B. M.; Khitrin, A. K.; Ermolaev, K. An Improved Broadband Decoupling Sequence for Liquid Crystals and Solids. J. Magn. Reson. 2000, 142, 97-101.

38. Ashbrook, S. E.; Wimperis, S. Spin-Locking of Quadrupolar Nuclei in Solids: Creation and Evolution of Coherences. J. Chem. Phys. 2004, 120, 2719-2731.

39. Ashbrook, S. E.; Wimperis, S. Spin-Locking of Half-Integer Quadrupolar Nuclei in Nuclear Magnetic Resonance of Solids: Second-Order Quadrupolar and Resonance Offset Effects. J. Chem. Phys. 2009, 131, 194509.

40. Lesage, A.; Bardet, M.; Emsley, L. Through-Bond Carbon-Carbon Connectivities in Disordered Solids by NMR. J. Am. Chem. Soc. 1999, 121, 10987-10993.

41. Fyfe, C. A.; Wong-Moon, K. C.; Huang, Y.; Grondey, H. INEPT Experiments in SolidState NMR. J. Am. Chem. Soc. 1995, 117, 10397-10398.

42. De Vita, E.; Frydman, L. Spectral Editing in ${ }^{13} \mathrm{C}$ MAS NMR under Moderately Fast Spinning Conditions. J. Magn. Reson. 2001, 148, 327-337.

43. Guillion, T; Schaefer, J. Rotational-Echo Double-Resonance NMR. J. Magn. Reson. 1989, 81, 196-200.

44. States, D. J.; Haberkorn, R. A.; Ruben, D. J. A Two-Dimensional Nuclear Overhauser Experiment with Pure Absorption Phase in 4 Quadrants. J. Magn. Reson. 1982, 48, 286-292. 
45. Massiot, D.; Fayon, F.; Capron, M.; King, I.; Le Calvé, S.; Alonso, B.; Durand, J. O.; Bujoli, B.; Gan, Z.; Hoatson, G. Modelling One and Two-Dimensional Solid-State NMR Spectra. Magn. Reson. Chem. 2002, 40, 70-76.

46. McMillan, M.; Brinen, J. S.; Carruthers, J. D.; Haller, G. L. A ${ }^{29}$ Si NMR Investigation of the Structure of Amorphous Silica-Alumina Supports. Colloids Surf. 1989, 38, 133-148.

47. Sato, S.; Sodesawa, T.; Nozaki, F. Solid-State NMR of Silica-Alumina Prepared by Chemical Vapor Deposition. J. Mol. Catal. 1991, 66, 343-355.

48. Koller, H.; Weiß, M. Solid State NMR of Porous Materials: Zeolites and Related Materials. Top. Curr. Chem. 2012, 306, 189-228.

49. Lippmaa, E.; Magi, M.; Samoson, A.; Engelhardt, G.; Grimmer, A. R. Structural Studies of Silicates by Solid-State High-Resolution ${ }^{29 S i ~ N M R . ~ J . ~ A m . ~ C h e m . ~ S o c . ~ 1980, ~ 102, ~ 4889-~}$ 4893.

50. Kinney, D. R.; Chuang, I. S.; Maciel, G. E. Water and the Silica Surface as Studied by Variable-Temperature High-Resolution ${ }^{1} \mathrm{H}$ NMR. J. Am. Chem. Soc. 1993, 115, 6786-6794.

51. Kim, H. N.; Lee, S. K. Atomic Structure and Dehydration Mechanism of Amorphous Silica: Insights from ${ }^{29} \mathrm{Si}$ and ${ }^{1} \mathrm{H}$ Solid-State MAS NMR Study of $\mathrm{SiO}_{2}$ Nanoparticles. Geochim. Cosmochim. Acta 2013, 120, 39-64.

52. Florian, P.; Fayon, F.; Massiot, D. ${ }^{2} \mathrm{~J}$ Si-O-Si Scalar Spin-Spin Coupling in the Solid State: Crystalline and Glassy Wollastonite CaSiO3. J. Phys. Chem. C 2009, 113, 2562-2572.

53. Florian, P.; Veron, E.; Green, T. F. G.; Yates, J. R., Massiot, D. Elucidation of the Al/Si Ordering in Gehlenite $\mathrm{Ca}_{2} \mathrm{Al}_{2} \mathrm{SiO}_{7}$ by Combined ${ }^{29} \mathrm{Si}$ and ${ }^{27} \mathrm{Al} \quad \mathrm{NMR}$ Spectroscopy/Quantum Chemical Calculations. Chem. Mater. 2012, 24, 4068-4079.

54. Huggins, B. A.; Ellis, P. D. Aluminum-27 Nuclear Magnetic Resonance Study of Aluminas and their Surfaces. J. Am. Chem. Soc. 1992, 114, 2098-2108.

55. Taoufik, M.; Szeto, K. C.; Merle, N.; Del Rosal, I.; Maron, L.; Trebosc, J.; Tricot, G.; Gauvin, R. M.; Delevoye, L. Heteronuclear NMR Spectroscopy as a Surface-Selective Technique: A Unique Look at the Hydroxyl Groups of $\gamma$-Alumina. Chem. Eur. J. 2014, 20, 4038-4046. 
56. Lee, D.; Duong, N. T.; Lafon, O.; De Paepe, G. Primostrato Solid-State NMR Enhanced by Dynamic Nuclear Polarization: Pentacoordinated $\mathrm{Al}^{3+}$ Ions Are Only Located at the Surface of Hydrated $\gamma$-Alumina. J. Phys. Chem. C 2014, 118, 25065-25076.

57. Wang, Z.; Jiang, Y.; Lafon, O.; Trébosc, J; Kim, K. D.; Stampfl, C.; Baiker, A.; Amoureux, J-P.; Huang, J. Brønsted Acid Sites Based on Penta-Coordinated Aluminum Species. Nature Commun. 2016, 7:13820, 1-4.

57. Sindorf, D. W.; Maciel G. E. Silicon-29 Nuclear Magnetic Resonance Study of Hydroxyl Sites on Dehydrated Silica Gel Surfaces, Using Silylation as a Probe. J. Phys. Chem. 1983, 87, 5516-5521.

58. Zhao, X. S.; Lu, G. Q.; Whittaker, A. K.; Millar, G. J.; Zhu, H. Y. Comprehensive Study of Surface Chemistry of MCM-41 Using ${ }^{29 S i ~ C P / M A S ~ N M R, ~ F T I R, ~ P y r i d i n e-T P D, ~ a n d ~}$ TGA. J. Phys. Chem. B 1997, 101, 6525-6531. 
Table 1. ${ }^{29} \mathrm{Si}$ chemical shifts $\left(\delta_{\text {iso }}\right)$, relative intensities and assignments for the contributions to the ${ }^{29} \mathrm{Si}$ MAS NMR spectrum of $99 \%{ }^{29}$ Si-enriched $\mathrm{Si}-\gamma-\mathrm{Al}_{2} \mathrm{O}_{3}(1.5 \mathrm{wt} \% \mathrm{Si})$ shown in Figure 6.

\begin{tabular}{cccc}
\hline Component & $\delta_{\text {iso }}(\mathrm{ppm})$ & Relative intensity (\%) & Assignment \\
\hline 1 & $-77(1)$ & $22(2)$ & $\mathrm{Q}^{1}(1 \mathrm{Al})$ \\
2 & $-80(1)$ & $14(3)$ & $\mathrm{Q}^{2}(2 \mathrm{Al})$ \\
3 & $-83(1)$ & $34(2)$ & $\mathrm{Q}^{3}(3 \mathrm{Al}) / \mathrm{Q}^{4}(4 \mathrm{Al})$ \\
4 & $-89(2)$ & $30(2)$ & $\mathrm{Q}^{4}(3 \mathrm{Al})$ \\
\hline
\end{tabular}




\section{Figure captions}

Figure 1. ${ }^{29} \mathrm{Si}$ and ${ }^{1} \mathrm{H}-29 \mathrm{Si}\left(9.4 \mathrm{~T}, 10-14 \mathrm{kHz}\right.$ MAS) NMR spectra of 99\% ${ }^{29} \mathrm{Si}-\mathrm{enriched} \mathrm{Si}-\gamma$ $\mathrm{Al}_{2} \mathrm{O}_{3}(1.5 \mathrm{wt} \% \mathrm{Si})$, acquired using (a) direct polarization (DP), (b) cross polarization (CP) and (c) DNP. DP and CP spectra were acquired at room temperature on samples that had no radical added. The DNP spectrum was performed at $100 \mathrm{~K}$. Spectra are the result of averaging (a) 504, (b) 14400 and (c) 32 transients with recycle intervals of (a) 120, (b) 1 and (c) 3 s. For CP and DNP spectra, a contact pulse duration of 3 ms was used.

Figure 2. (a) ${ }^{1} \mathrm{H}-29 \mathrm{Si}\left(9.4 \mathrm{~T}, 10 \mathrm{kHz}\right.$ MAS) $\mathrm{CP}$ NMR spectra of $99 \%$ ${ }^{29} \mathrm{Si}$-enriched $\mathrm{Si}-\gamma-\mathrm{Al}_{2} \mathrm{O}_{3}$ (1.5 wt\% Si), acquired by averaging 14400 transients separated by a recycle interval of $1 \mathrm{~s}$, using $\tau_{\mathrm{CP}}$ values between 0.1 and $10 \mathrm{~ms}$. (b) Comparison of ${ }^{1} \mathrm{H}-{ }^{29} \mathrm{Si}(9.4 \mathrm{~T}, 10 \mathrm{kHz} \mathrm{MAS}) \mathrm{CP}$ NMR spectra of hydrated (black line) and dehydrated (red line) 99\% 29Si-enriched Si- $\gamma$ $\mathrm{Al}_{2} \mathrm{O}_{3}(1.5 \mathrm{wt} \% \mathrm{Si}$ ). Spectra are the result of averaging 14400 (hydrated) and 34000 (dehydrated) transients separated by a recycle interval of $1 \mathrm{~s}$. Polarization transfer (from $\left.{ }^{1} \mathrm{H}\right)$ was achieved using $\tau_{\mathrm{CP}}$ values of $3 \mathrm{~ms}$. In each case, the spectral intensities have been normalized.

Figure 3. ${ }^{1} \mathrm{H}-29 \mathrm{Si}(9.4 \mathrm{~T}, 10 \mathrm{kHz}$ MAS) CP HETCOR NMR spectra of $29 \mathrm{Si}$-enriched Si- $\gamma$ $\mathrm{Al}_{2} \mathrm{O}_{3}(1.5 \mathrm{wt} \% \mathrm{Si})$, demonstrating the effect of (a) the hydration level of the sample and (b) $\tau_{\mathrm{CP}}$ on the dehydrated material. In (a), the spectrum of the hydrated material is the result of averaging 880 transients separated by a recycle interval of $1 \mathrm{~s}$, for each of $20 \mathrm{t}_{1}$ increments of $100 \mu \mathrm{s}$. The spectrum of the dehydrated material is the result of averaging 1600 transients separated by a recycle interval of $1 \mathrm{~s}$, for each of $18 \mathrm{t}_{1}$ increments of $50 \mu \mathrm{s}$. A CP contact time of $0.5 \mathrm{~ms}$ was employed in both instances. In (b), both spectra were acquired by averaging 1600 transients separated by a recycle interval of $1 \mathrm{~s}$, for each of 18 $\mathrm{t}_{1}$ increments of $50 \mu \mathrm{s}$.

Figure 4. ${ }^{29} \mathrm{Si}(9.4 \mathrm{~T}, 12.5 \mathrm{kHz} \mathrm{MAS})$ refocused CP INADEQUATE DNP NMR spectrum of hydrated ${ }^{29} \mathrm{Si}$-enriched $\mathrm{Si}-\gamma-\mathrm{Al}_{2} \mathrm{O}_{3}(1.5 \mathrm{wt} \% \mathrm{Si})$. The spectrum is the result of averaging 96 
transients separated by a recycle interval of $3 \mathrm{~s}$ for each of the $48 \mathrm{t}_{1}$ increments of $80 \mu \mathrm{s}$, with a $\tau_{\mathrm{J}}$ value of $9.6 \mathrm{~ms}$. Polarization transfer was achieved using a $\tau_{\mathrm{CP}}$ value of $3 \mathrm{~ms}$. (b) Overlay of $\left(\delta_{2}\right)$ projections of two-dimensional refocused INADEQUATE DNP NMR spectra (shown in the Supporting Information) as a function of $\tau_{\mathrm{J}}$ time. The ${ }^{1} \mathrm{H}-{ }^{29} \mathrm{Si} \mathrm{CP}$ DNP NMR spectrum is also shown for comparison.

Figure 5. ${ }^{29} \mathrm{Si}^{27} \mathrm{Al}(9.4 \mathrm{~T}, 10 \mathrm{kHz} \mathrm{MAS}) \mathrm{CP}$ INEPT DNP NMR spectrum of hydrated ${ }^{29} \mathrm{Si}-$ enriched $\mathrm{Si}-\gamma-\mathrm{Al}_{2} \mathrm{O}_{3}(1.5 \mathrm{wt} \% \mathrm{Si})$, with transfer via the (a) dipolar and (b) scalar coupling. Spectra are the result of averaging (a) 48 and (b) 224 transients separated by a recycle interval of $2 \mathrm{~s}$ for each of $32 \mathrm{t}_{1}$ increments of $100 \mu \mathrm{s}$. In (b), recoupling of the dipolar interaction was carried out using 4 REDOR blocks of 8 rotor cycles (of $100 \mu$ s) in duration. Polarization transfer was achieved using a $\tau_{\mathrm{CP}}$ value of $3 \mathrm{~ms}$.

Figure 6. (a) ${ }^{29} \mathrm{Si}(9.4 \mathrm{~T}, 14 \mathrm{kHz}$ MAS) experimental (blue) and simulated (red) NMR spectra of hydrated ${ }^{29} \mathrm{Si}$-enriched $\mathrm{Si}-\gamma-\mathrm{Al}_{2} \mathrm{O}_{3}(1.5 \mathrm{wt} \% \mathrm{Si})$. Also shown are the individual components of the fit (green). The experimental spectrum is the result of averaging 504 transients separated by a recycle interval of 120 s. (b) Assignment of the proposed structural motifs present. 
Figure 1

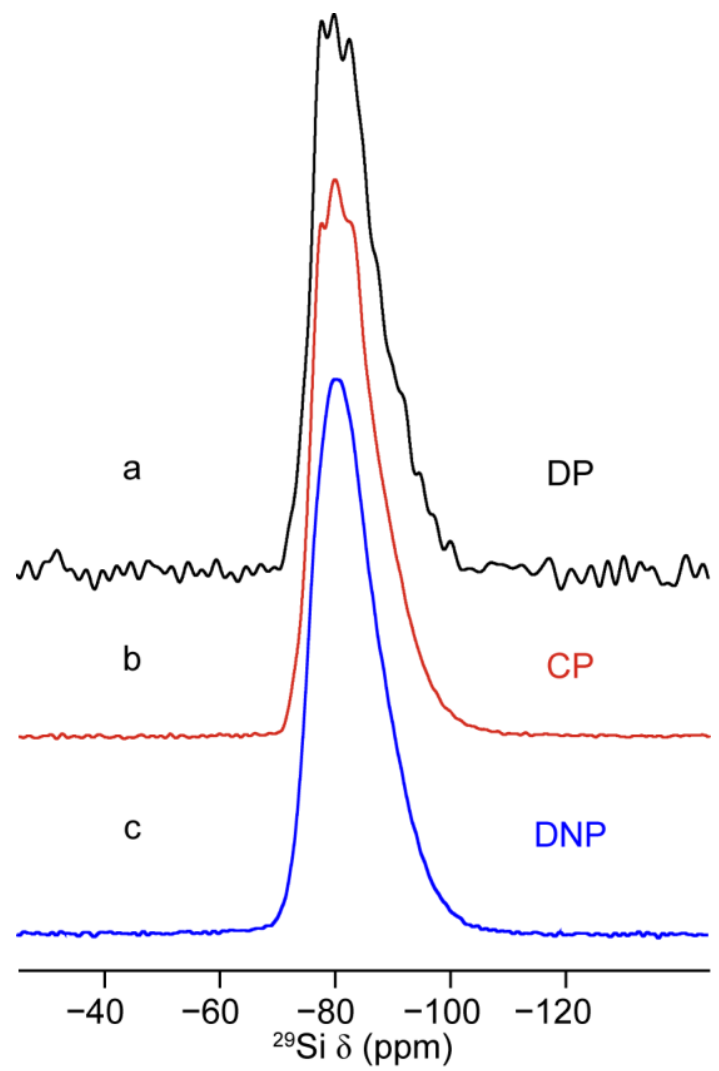

Figure 2
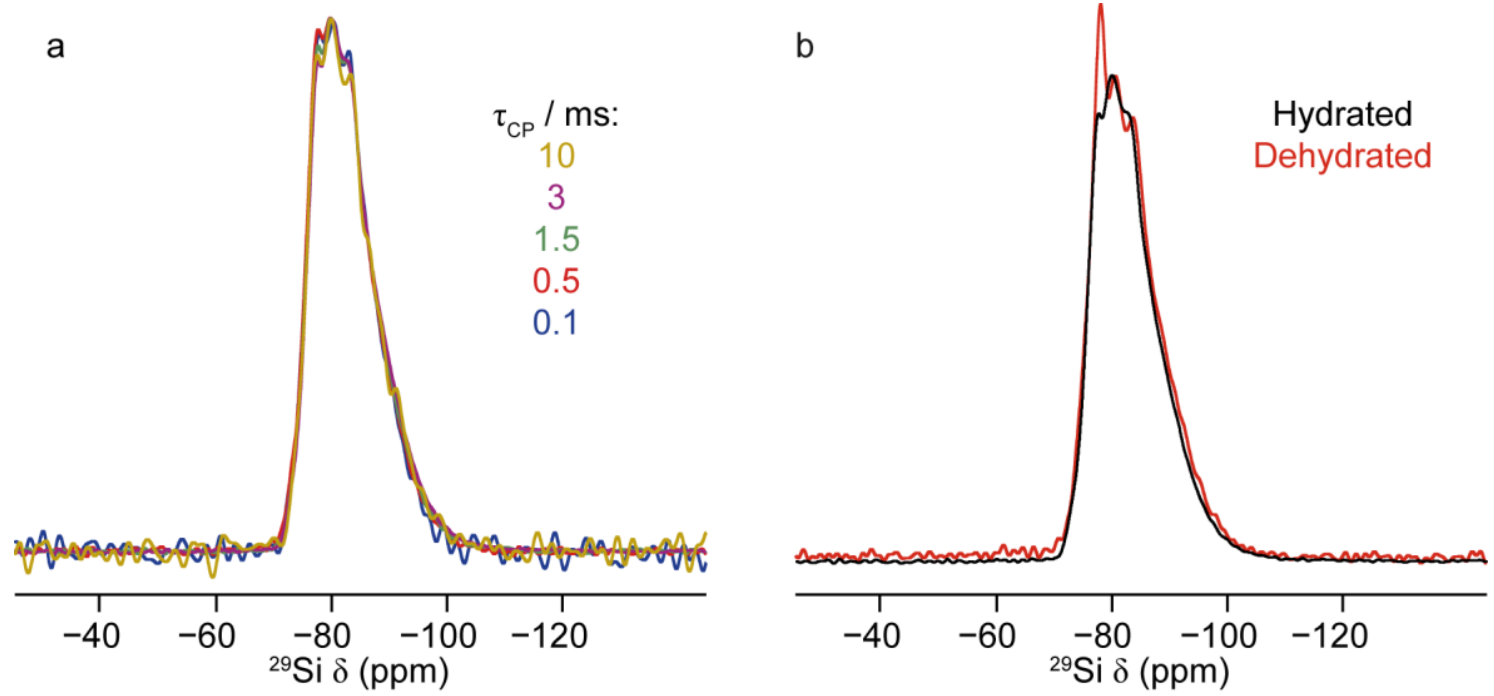
Figure 3
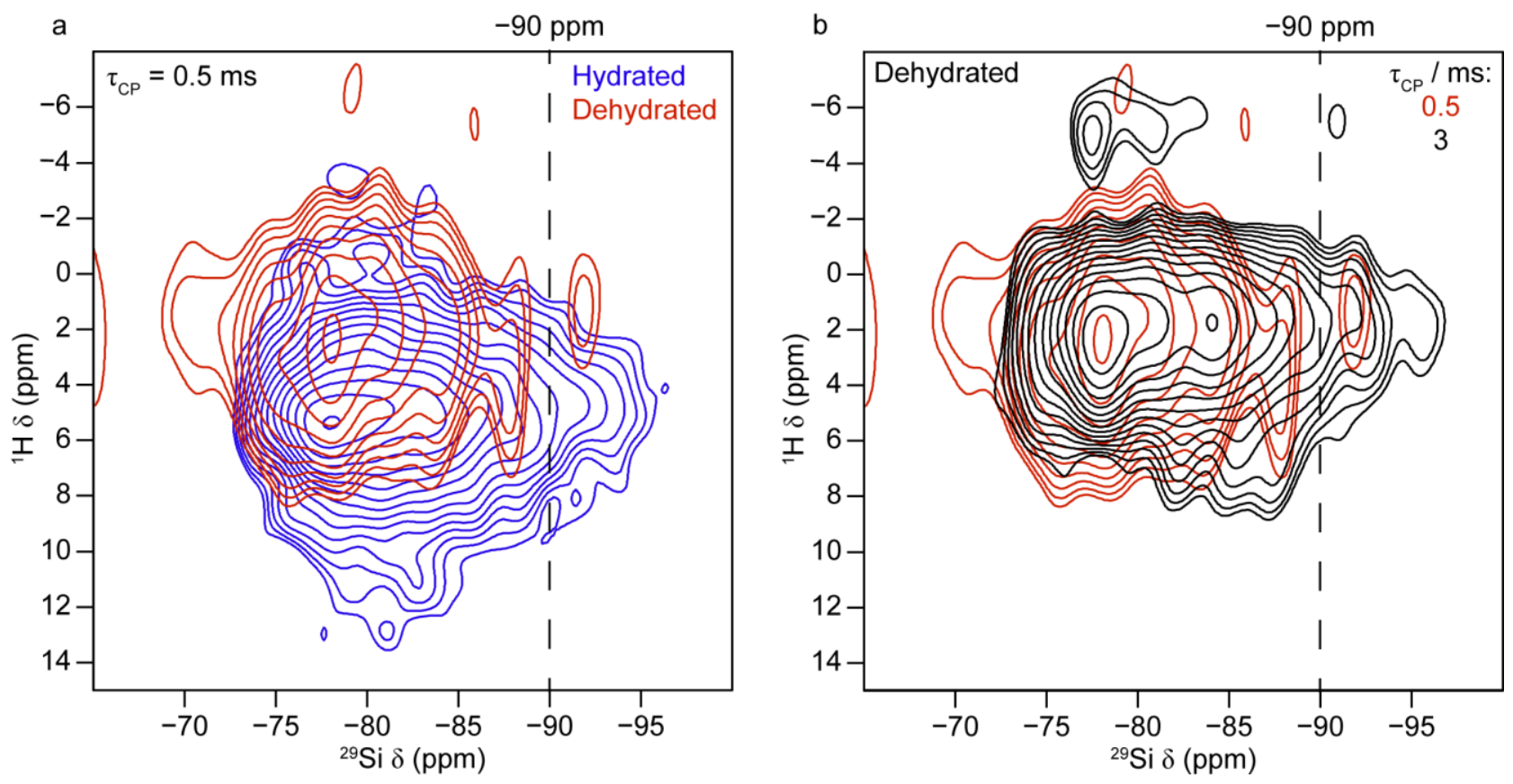

Figure 4

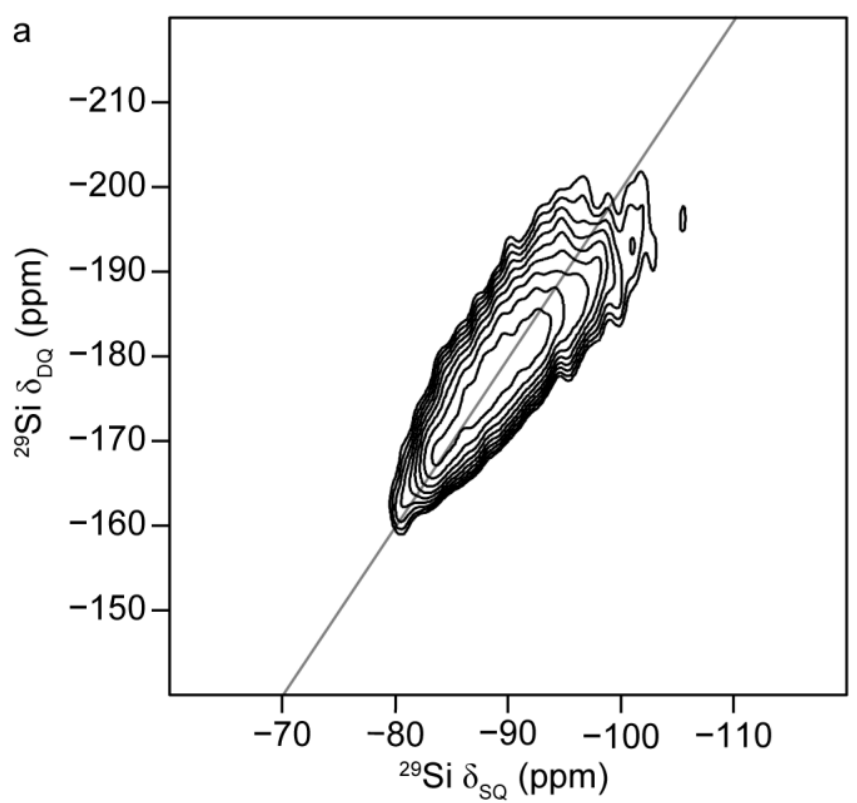

b

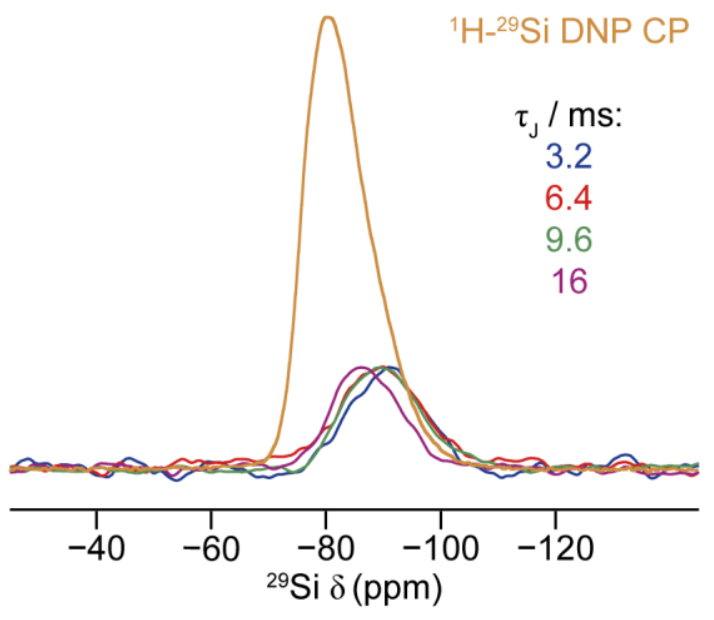


Figure 5
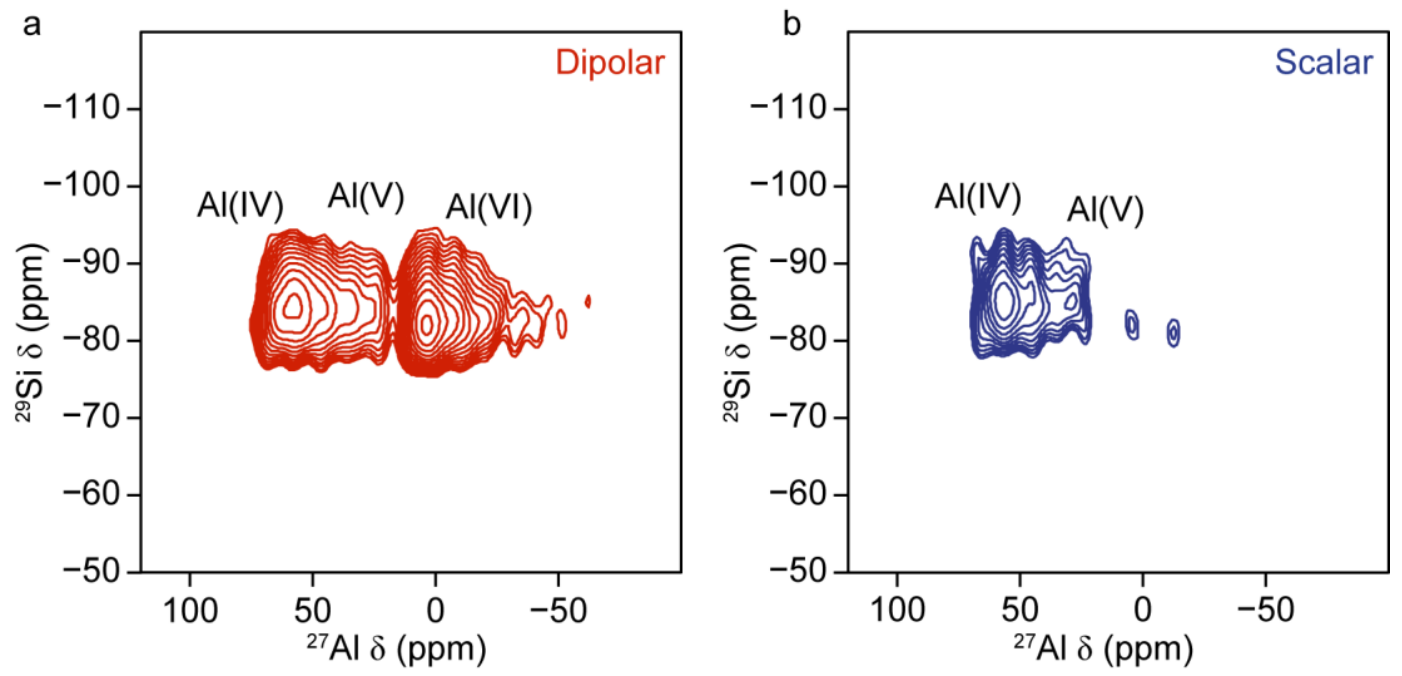

Figure 6
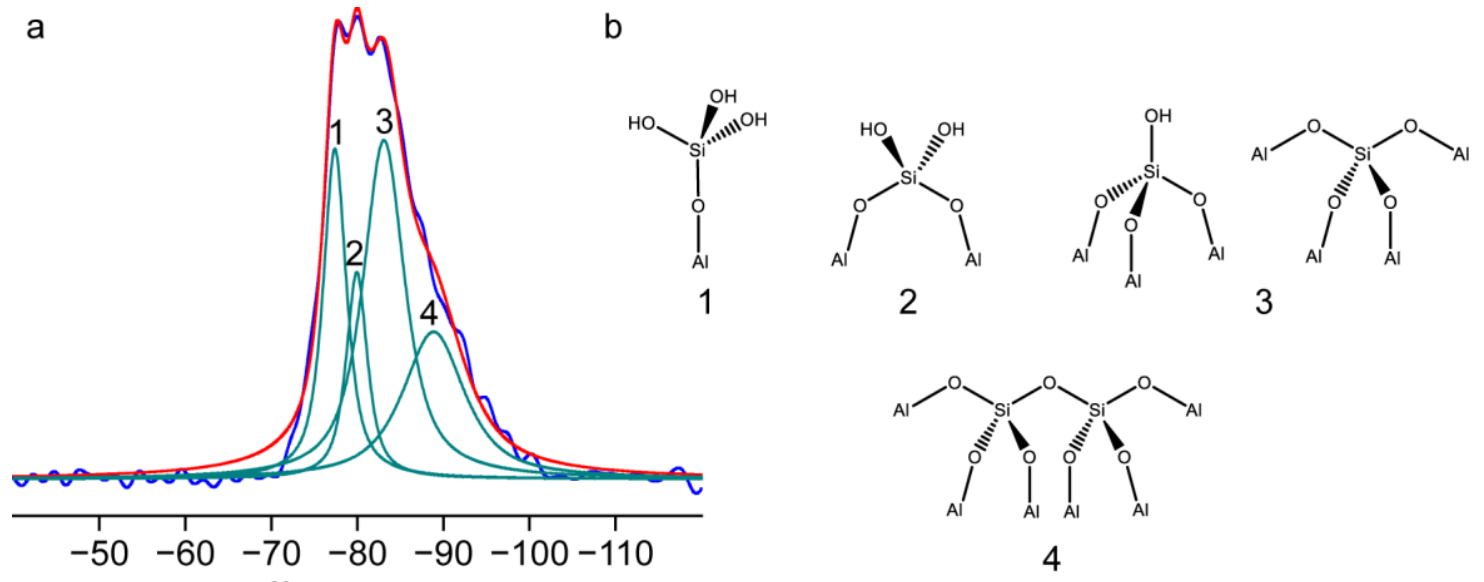

${ }^{29} \mathrm{Si} \delta(\mathrm{ppm})$ 
TOC Graphic

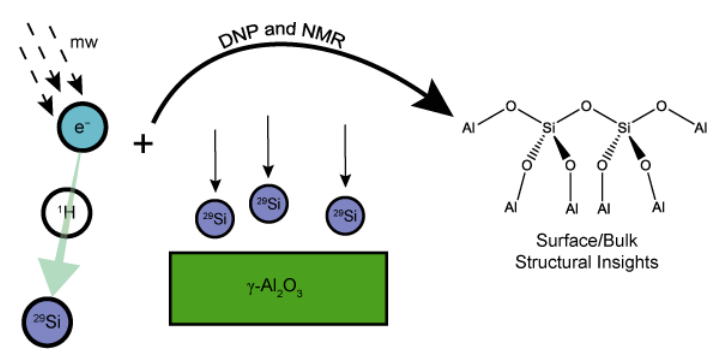

